\title{
Deciphering miRNA transcription factor feed-forward loops to identify drug repurposing candidates for cystic fibrosis
}

\author{
Zhichao Liu', Jürgen Borlak ${ }^{2^{*}}$ and Weida Tong ${ }^{1^{*}}$
}

\begin{abstract}
Background: Cystic fibrosis (CF) is a fatal genetic disorder caused by mutations in the CF transmembrane conductance regulator (CFTR) gene that primarily affects the lungs and the digestive system, and the current drug treatment is mainly able to alleviate symptoms. To improve disease management for $C F$, we considered the repurposing of approved drugs and hypothesized that specific microRNA (miRNA) transcription factors (TF) gene networks can be used to generate feed-forward loops (FFLs), thus providing treatment opportunities on the basis of disease specific FFLs.
\end{abstract}

Methods: Comprehensive database searches revealed significantly enriched TFs and miRNAs in CF and CFTR gene networks. The target genes were validated using ChIPBase and by employing a consensus approach of diverse algorithms to predict miRNA gene targets. STRING analysis confirmed protein-protein interactions (PPIs) among network partners and motif searches defined composite FFLs. Using information extracted from SM2miR and Pharmaco-miR, an in silico drug repurposing pipeline was established based on the regulation of miRNA/TFs in CF/CFTR networks.

Results: In human airway epithelium, a total of 15 composite FFLs were constructed based on CFTR specific miRNA/TF gene networks. Importantly, nine of them were confirmed in patient samples and CF epithelial cells lines, and STRING PPI analysis provided evidence that the targets interacted with each other. Functional analysis revealed that ubiquitin-mediated proteolysis and protein processing in the endoplasmic reticulum dominate the composite FFLs, whose major functions are folding, sorting, and degradation. Given that the mutated CFTR gene disrupts the function of the chloride channel, the constructed FFLs address mechanistic aspects of the disease and, among 48 repurposing drug candidates, 26 were confirmed with literature reports and/or existing clinical trials relevant to the treatment of CF patients.

Conclusion: The construction of FFLs identified promising drug repurposing candidates for CF and the developed strategy may be applied to other diseases as well.

\section{Background}

Cystic fibrosis (CF) is a lethal autosomal recessive disorder that mostly affects Caucasians with approximately 30,000 cases in the United States and about 70,000 cases reported worldwide. It is caused by mutations in the CF transmembrane conductance regulator (CFTR) gene [1] which codes

\footnotetext{
* Correspondence: Borlak.Juergen@mh-hannover.de; weida.tong@fda.hhs.gov ${ }^{2}$ Centre for Pharmacology and Toxicology, Hannover Medical School,

Carl-Neuberg-Straße 1, 30625 Hannover, Germany

1 Division of Bioinformatics and Biostatistics, National Center for Toxicological Research, U.S. Food and Drug Administration, 3900 NCTR Road, Jefferson, AR 72079, USA
}

for an ion channel to regulate the balance between the transport of chloride and the movement of water through an epithelial barrier. Mutations in the CFTR results in altered mucus and thickened secretions to promote chronic infection and inflammation [1]. Note that the mutations are grouped into different classes either affecting the quantity or function or a combination of both of the CFTR protein. Although the molecular causes for CF are well understood and >1,000 mutations have been identified, the treatment of CF is complex and mostly relies on the use of antibiotics. Currently, there is no cure for CF and drug treatment can only ease symptoms by influencing mucus 
production and the restoration of pulmonary surfactant, the prevention of inflammation and infection, and by the combined use of nutritional supplements [2]. Despite some advances in the treatment and management of disease, the median age of survival for CF patients is still only about 40 years [2].

In 2012, the US Food and Drug Administration (FDA) approved Kalydeco (ivacaftor) for its use in CF patients. This drug modulates CFTR activity and fulfilled a promise made more than 20 years ago when a mutated CFTR was first discovered and researchers spoke optimistically about developing drugs to restore the function of the mutated protein [3]. The successful development of Kalydeco is a milestone in the treatment of CF patients; however whether patients will be able to afford the drug is unclear, making its widespread adoption and use questionable. In the UK, regulators only agreed to approve Kalydeco after Vertex Pharmaceuticals reduced its official list price to $£ 182,625$ ( $\$ 297,000)$ per year per patient [4] and the drug is intended for use in CF patients of the G551D genotype only and must be aged 6 years and above.

Importantly, to address unmet needs in rare and neglected diseases, drug repurposing of approved drugs has been advocated and attracted significant attention from academia, pharmaceutical industry and governmental agencies $[5,6]$ and included the use of statins (e.g., simvastatin) for the treatment of adult CF [7]. Apart from its lipid-lowering effects, statins influence the production of pro-inflammatory cytokines and chemokines. Moreover, statins modulate nitric oxide (NO) production by inhibiting the RhoGTPase pathway, thereby improving $\mathrm{NO}$ and inflammatory components in pathogen infected lungs of CF patients [8], as evidenced in clinical studies $[9,10]$.

An identification of drug-repurposing candidates for CF based on a systematic analysis of an entire drug landscape has not been attempted. We therefore explored a computational strategy based on the drug-repurposing principle that integrates diverse data, including data from emerging molecular technologies such as expression of microRNA (miRNA), and transcription factors (TFs) to promote the rational use of market drugs for the treatment of CF.

For this purpose, feed-forward loops (FFL) were constructed and FFLs are defined as regulatory network motifs, whose connectivity patterns occur much more frequently than randomized in 'control' networks [11]. A FFL usually consists of two regulatory elements, one of which controls the other to regulate gene expression together [11]. FFLs have been demonstrated to play important roles in disease development and contributed to an understanding of underlying mechanism [12]. For instance, the two regulatory elements can be defined as two TFs or one TF plus one miRNA. Taylor et al. [13] detected a nuclear factor, erythroid 2-related factor (Nrf2), that regulated a FFL which was involved in the protective response to oxidative stress in a mouse disease model. Hall et al. [12] reported a type I interferon (IFN) FFL in the pathogenesis of autoimmune rheumatic diseases. Guo et al. [14] identified 32 schizophrenia specific FFLs consisting of miRNA, TF, and genes. Afshar et al. [15] explored FFLs entailing miRNAs, TFs, and genes in prostate cancer. These proof of concept studies encourage the development of disease specific FFL that can be applied to the process of drug repurposing. Here we hypothesized the existence of a set of FFLs in CF where the two regulatory elements are defined by specific TFs and miRNAs, respectively.

Notably, miRNAs are 18 to $25 \mathrm{nt}$ long non-coding RNAs that function in the transcriptional and post-transcriptional regulation of gene expression [16]. miRNAs are involved in different biological processes such as differentiation, apoptosis, and stress response [17], and miRNAs can interact with the 3'UTR of target mRNAs via base-pairing to facilitate the recruitment of a ribonucleoprotein complex that either blocks cap-dependent translation or triggers target mRNA deadenylation and degradation [17]. An increasing number of miRNAs have been identified to regulate cancers $[18,19]$, multiple sclerosis [20], diabetes [21], hepatotoxicity [22], and cardiovascular diseases [23]. miRNAs have also been reported to play a crucial post-transcriptional role in CF [24-28]. For example, miR-126 was shown to regulate the inflammatory signaling pathway and was reported to be decreased in CF respiratory epithelium as compared to nonCF bronchial epithelial cells in vivo and in vitro [29]. Likewise, TFs are key regulators in the control of gene expression by translating cis-regulatory codes [30]. Due to their function and regulatory logic [31], miRNA and TFs coregulate the same genes in a complex manner and are therefore suitable elements to construct FFLs.

We therefore hypothesized the existence of a set of FFLs which are composed of both TFs and miRNA to regulate genes in CF and CFTR. Consequently, we constructed CF and CFTR-specific FFLs, and studied the effects of market drugs by inferring perturbations of disease-specific FFLs with the aim to determine their potential utility in the treatment of CF. We focused on approved drugs without boxed warning and are considered to be safe at affordable prices. As a result, we identified market drugs as putative candidates for $\mathrm{CF}$ treatment. Strikingly, out of the 48 repurposing drug candidates 26 were confirmed with literature reports and/or existing clinical trials relevant to the treatment of CF patients thus providing evidence for the utility of the employed approach.

\section{Material and methods}

\section{CF and CFTR associated gene regulations}

Initially, we collected information from diverse public repositories including the Genetic Association Database 
(GAD) [32,33], Orphanet [34,35], the Online Mendelian Inheritance in Man (OMIM) [36,37], the Function disease ontology annotation (FunDO) [38,39], and PubMed reports (see also Table 1). The broad and diverse information was validated by different experimental platforms. Eventually, a comprehensive list of differentially expressed genes (DEG) was compiled using diverse data sets from cystic fibrosis patients with mild and severe lung disease based on tissue samples obtained from bronchial brushings or nasal epithelium as well as rectal epithelia of CF and non-CF individuals (GEO submission GSE2395, GSE55146, and GSE15568). Collectively, a total of 1,042 DEGs were compiled (Additional file 1: Table S1). To discern CFTRassociated gene regulations from CF-related DEGs the data reported by Ramachandran et al. [25] were considered and included 419 unique genes (Additional file 1: Table S1).

\section{MiRNA networks of CF-regulated genes (miRNA $\rightarrow$ gene/TF)}

To identify CF-specific miRNAs, data from different sources were integrated, including a literature search using the keywords 'miRNA' and 'cystic fibrosis' in PubMed. Here, we focused on miRNA expression profiling studies in CF patient samples and considered particularly the findings of Oglesby et al. [40] and Bhattacharyya et al. [41] which had information on 93 and 22 regulated miRNAs, respectively.

Furthermore, to be able to distinguish between $\mathrm{CF}$ and CFTR miRNAs networks and to identify commonly regulated ones, data obtained from well-differentiated primary human airway epithelial cultures were considered as reported in Ramachandran et al. [25]. There were 112 CFTR associated miRNAs of note (Additional file 2: Table S2).
MiRNA analysis and target prediction was done with the TargetScan algorithm [42] and included the search for the presence of conserved $8 \mathrm{mer}$ or $7 \mathrm{mer}$ sites that match the seed region of the miRNA. The functional annotation of predicted targets is based on experimental validation $[43,44]$ and in the case of miRNA $\rightarrow$ gene/TF pairs to be considered conserved in homo sapiens a total context score higher than -0.4 was applied [45]. To confirm miRNA targets in CF and CFTR networks and to distinguish among individual TFs involved, the predicted target genes were mapped onto a human TFs list in the ChIPBase [46].

\section{Transcription factor networks of $\mathrm{CF}$ regulated genes (TF $\rightarrow$ gene/miRNA)}

The TF and gene/miRNA relationship data were extracted from the ChIPBase [46]. ChIPBase aims to provide high confident information on the transcriptional regulation of long non-coding RNA and miRNA genes from ChIP-Seq data. The data were curated from sources such as the NCBI GEO database [47], ENCODE [48], the modENCODE databases $[49,50]$, and PubMed literature citations. Thus, the TFs related to CF and CFTR gene/miRNA networks were extracted from the human hg19 organism with regulatory regions (upstream: $5 \mathrm{~kb}$; downstream: $1 \mathrm{~kb}$ ).

\section{CF protein-protein interaction network}

The STRING 9.1 version [51] was applied to study proteinprotein-interaction (PPI) using input data derived from [27] and CF patient samples (GEO submission GSE2395, GSE55146, and GSE15568). Initially, a total of 123 CFTRassociated genes were considered and based on 80 genes that are part of the 15 constructed FFLs. A total of 135 PPIs

Table 1 Summary of genes and miRNAs used in this study

\begin{tabular}{lrl}
\hline CF-related miRNAs/genes & & CFTR-related miRNAs/genes \\
miRNAs & 1 & TLDA experiment \\
\hline HMDD & 0 & Genes \\
miR2Disease & 7 & Literatures \\
PhenomiR & 22 & \\
Literatures & 93 & \\
Bhattacharyya et al. data & & \\
Oglesby et al. & 19 & \\
Genes & 3 & \\
GAD & 4 & \\
Orphanet & 49 & \\
OMIM & 565 & \\
Disease Ontology & 393 & \\
Nasal respiratory epithelial (GSE2395) & 96 & \\
Human bronchial epithelium (GSE55146) & & \\
Human epithelial cells (GSE15568) & & \\
\hline
\end{tabular}


were observed. Furthermore, for nine disease-specific FFLs and the 66 genes associated with it, a total of 97 PPIs were observed. Additionally, for nine out of 15 FFLs the diseasespecific regulation of miRNA was validated by a consensus approach by employing 10 different algorithms, that is, DIANA-microT [52], miRanda [53], miRDB [54], miRWalk [55], RNAhybrid [56], PICTAR4 [57], PICTAR5 [57], PITA [58], RNA22 [59], and TargetScan [60] (see Figure 1). Gene targets were considered positive only when confirmed by at least eight algorithms. Importantly, the STRING analysis provided high confidence PPI interactions based on the neighborhood, gene fusion, co-occurrence, co-expression, experiments, text-mining, and so on. In this study, only interactions with confidence scores higher than 0.4 were extracted.

\section{Enrichment of significantly regulated miRNA and TF in CF gene networks}

To assess the statistical significance for genes that were co-regulated by both miRNA and TF, the cumulative hypergeometric test was employed based on the common CF and CFTR-specific genes of any pair of miRNA and TF as described by the following formula [45]:

$$
\mathrm{p}=1-\Sigma_{0}^{\left|\mathrm{N}_{\text {miR }}\right| \cap\left|\mathrm{N}_{\mathrm{TF}}\right|}\left\{\left(\begin{array}{c}
\left|\mathrm{N}_{\text {miR }}\right| \\
\mathrm{i}
\end{array}\right)\left(\begin{array}{c}
\text { Total }-\left|\mathrm{N}_{\text {miR }}\right| \\
\left|\mathrm{N}_{\mathrm{TF}}\right|-\mathrm{i}
\end{array}\right)\right\} /\left(\begin{array}{c}
\text { Total } \\
\left|\mathrm{N}_{\mathrm{TF}}\right|
\end{array}\right),
$$

where $N_{m i R}$ denotes the number of target genes for a given miRNA, $N_{T F}$ represents the number of target genes for the corresponding TF, and Total is the number of common genes between all the CF- and CFTR-related genes regulated by TFs and repressed by miRNAs. The Benjamini-Hochberg multiple testing corrections were used to adjust the $P$ values (function mafdr.m from MATLAB 7.10.0 (R2010a)), and only those pairs with justified $P$ values less than 0.05 were considered.

\section{Drug effects on miRNA expression}

The effects of drugs on individual miRNAs were compiled from SM2miR [61]. In the present study, only FDA-approved drugs were considered to be potential repurposing candidates for CF. Moreover, the miRNAgene-drug relationship was extracted from PharmacomiR [62] that provides miRNA pharmacogenomics data manually curated from literatures.

\section{Results}

\section{CF- and CFTR-related gene and miRNA expression changes}

An outline of the work flow is given in Figure 1, and a summary of CF- and CFTR-related gene and miRNA data are given in Table 1. Initially, a comprehensive list of differentially expressed genes (DEG) was compiled using diverse data sets from CF patients in addition to literature findings regarding CFTR-associated gene networks. Subsequently, common regulations of DEGs by TFs and miRNAs were investigated by means of databases searches in addition to experimental data retrieved from literature searches.

For this purpose, the publically available GEO data sets GSE2395, GSE55146, and GSE15568 were analyzed. The data informed on whole genome gene expression profiling in cystic fibrosis patients with mild and severe lung disease using either tissue samples obtained from bronchial brushings or nasal epithelium as well as rectal epithelia of $\mathrm{CF}$ and non-CF individuals. In all 1,042 DEGs were obtained, however there was little to no overlap among DEGs when individual studies were compared (see Figure 2A).

Furthermore, to discriminate CF-specific and CFTRrelated miRNA networks profiling data obtained from $\mathrm{CF}$ patient airway epithelium and CF related cell lines as well as primary human airway epithelium were considered using the findings reported by Oglesby et al. [40] and Bhattacharyya et al. [41]. As denoted for the whole genome gene expression profiling studies major discrepancies among the reported miRNA profiling studies were observed with little overlap in identified miRNAs using either bronchial brushings from CF patients or CF bronchial epithelial cell lines (see Figure 2B). In regards to the CFTR associated miRNA regulations the data reported by Ramachandran et al. [25] were used and yielded 112 differential expressed miRNAs. As depicted in Figure 2C, 31 down- and 12 upregulated miRNAs were in common when the findings of Oglesby et al. and CFTR-associated miRNAs were compared as determined in human airway epithelium. Likewise, two down- and 10 upregulated miRNAs were commonly regulated when the data reported by Bhattacharyya et al. and findings from CFTR-associated miRNAs were compared (Figure 2D). Taken collectively, a total of 93, 22, and 112 uniquely regulated miRNAs were extracted from experimental data and among the three studies seven miRNAs were in common that permitted an in-depth assessment of the miRNA-CF disease relationship.

Apart from CF-specific gene and miRNA expression changes several of the identified genes are also co-expressed or are involved in the same pathways or biological process as determined for the CFTR-associated gene network using human airway epithelium. This is consistent with our understanding of the pathogenesis of CF with most of the common regulated genes influencing folding, sorting, and degradation of proteins and included the ubiquitin mediated proteolysis, protein processing in the endoplasmic reticulum and the proteasome. It has been established that the ubiquitin-proteasome pathway controls the degradation of CFTR and therefore plays a central role in CF .

To be able to construct FFLs, different types of regulatory relationships were considered, that is, genes regulated by either miRNA (miRNA $\rightarrow$ gene) or TF (TF $\rightarrow$ gene), as well 


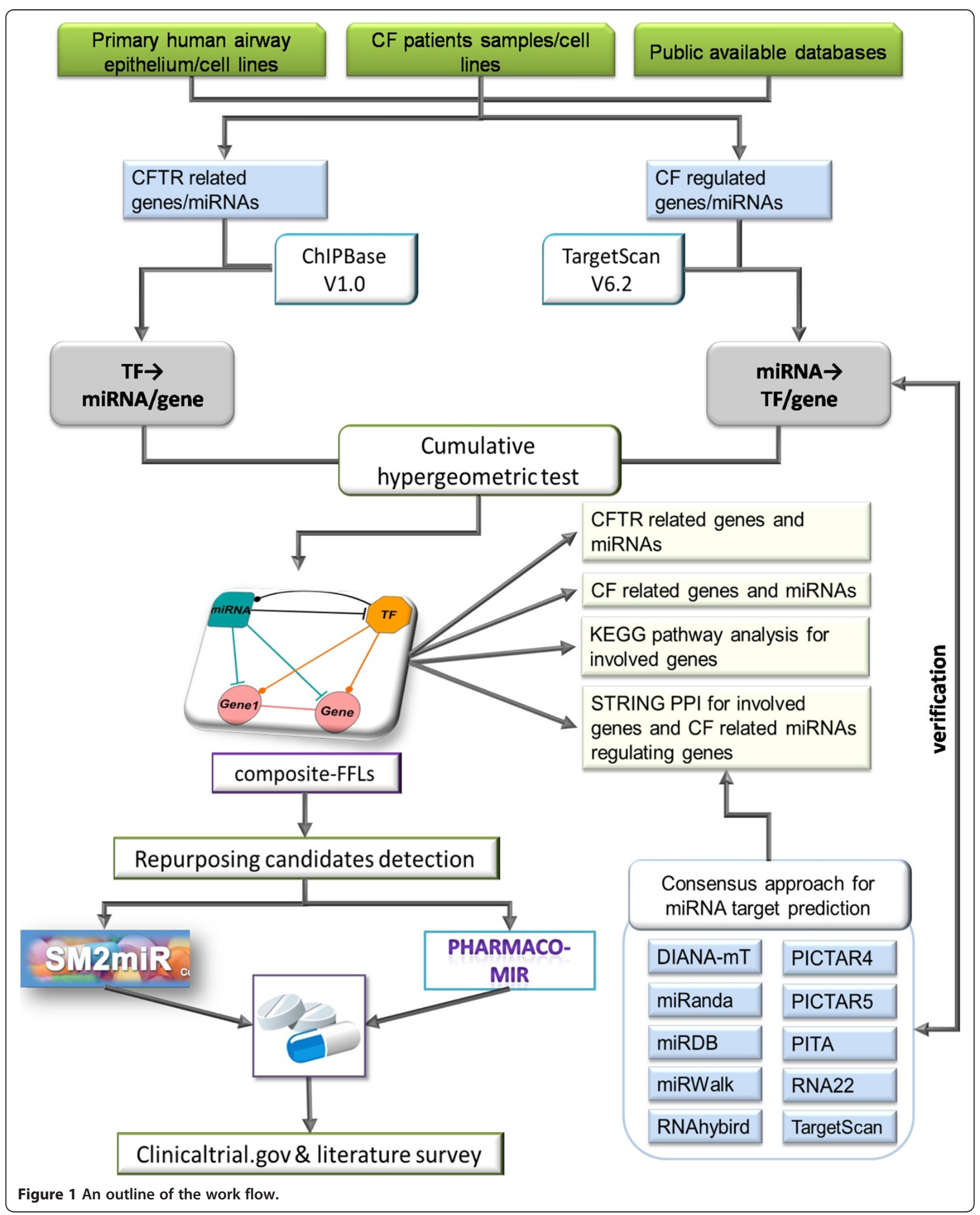




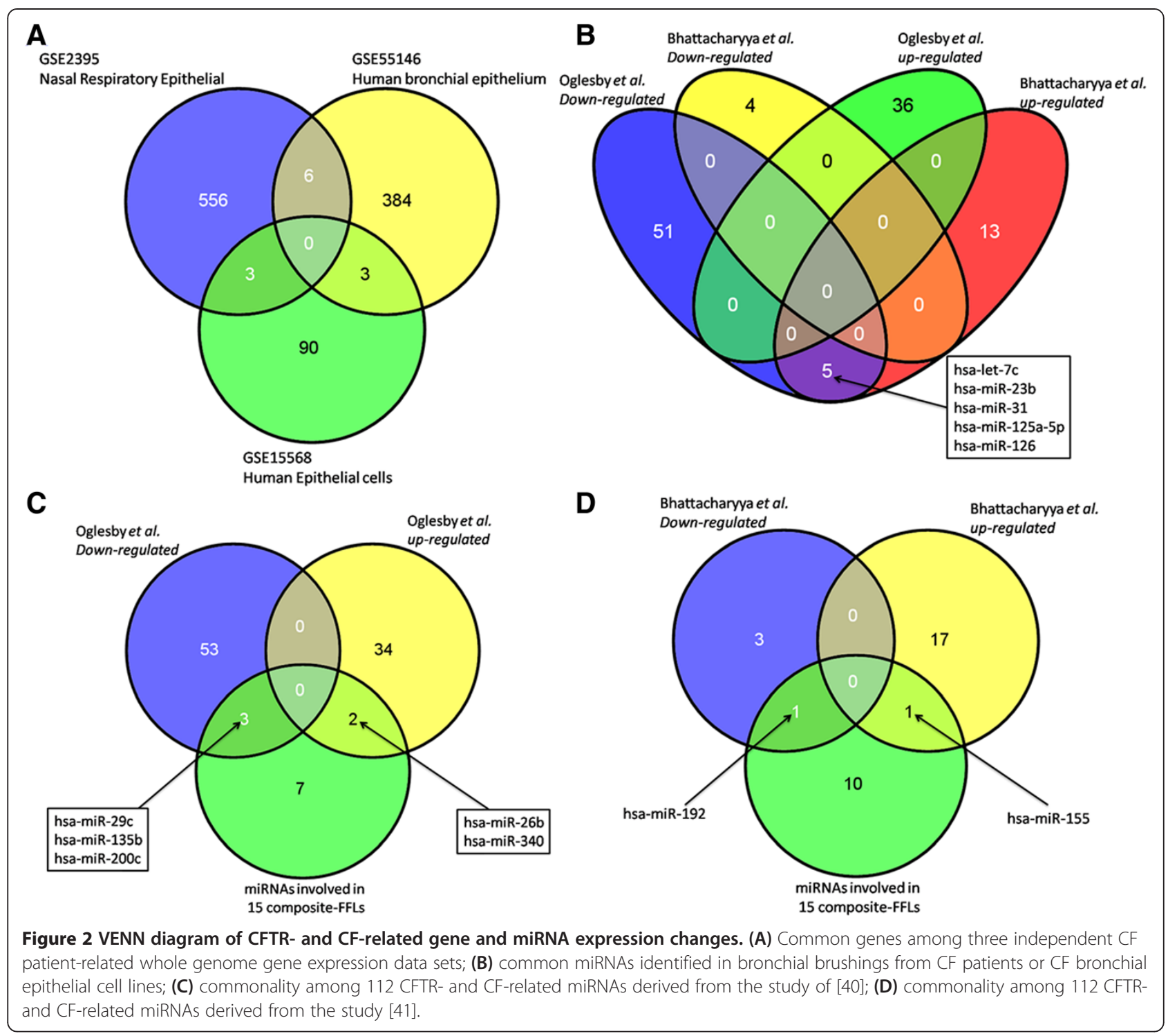

as the relationships between miRNA regulating TFs and vice versa (miRNA $\rightarrow \mathrm{TF}$ and $\mathrm{TF} \rightarrow$ miRNA) in addition to the gene-gene interaction as depicted in the work flow diagram (Figure 1 and Table 2). The findings entrained on the CFTR gene and miRNA networks were validated using data derived from CF patients as detailed in Table 2.

\section{miRNA gene target relationship}

Initially, the miRNA targets were predicted using TargetScan (see the Method Section for further details and Table 2). There were a total of 1,615 miRNA $\rightarrow$ gene pairs, which involved 99 CFTR specific miRNAs (out of 112 miRNAs identified) and 226 CFTR-regulated genes (out of 419 genes identified from Reference [25]). Among them, the miRNAs, hsa-miR-200b, hsa-miR-200c, and hsa-miR429 regulated the largest number of genes. The average number of targeted genes per miRNA is 16.
It is well known that the miRNAs from the same family share similar regulatory functions and mechanisms [63]. We therefore constructed a miRNA-based network using the CF gene information and investigated whether the relationship between the miRNAs from the same family was preserved as a means to verify the chosen approach. Figure 2 depicts the miRNAs network module where each node is a CF miRNA while an edge denotes the Tanimoto similarity between each of the two miRNAs. It can therefore be demonstrated that the miRNAs from the same family (for example, $h s a-l e t-7 a / b / c / e / g$ ) were preserved with higher Tanimoto similarity. Likewise, in the constructed miRNA-gene network NEDD4L was regulated by 33 miRNAs. This gene codes for an E3 ubiquitin protein ligase and knockdown of NEDD4L in lung epithelia causes airway mucus obstruction, goblet cell hyperplasia, inflammation, fibrosis, and even death after 3 weeks of exposure 
Table 2 Summary of five different kinds of regulatory relationship and constructed FFLs

\begin{tabular}{|c|c|c|c|c|c|}
\hline Relationship & & Counts & miRNAs (n) & mRNAs (n) & TFs (n) \\
\hline \multirow[t]{5}{*}{ Five regulatory relationships } & $\mathrm{miRNA} \rightarrow \mathrm{mRNA}$ & 1,615 & 99 & 226 & - \\
\hline & miRNA $\rightarrow$ TF & 422 & 89 & - & 52 \\
\hline & $\mathrm{TF} \rightarrow \mathrm{miRNA}$ & 3,295 & 102 & - & 114 \\
\hline & $\mathrm{TF} \rightarrow \mathrm{mRNA}$ & 16,860 & - & 387 & 105 \\
\hline & gene-gene & 237 & & 123 & \\
\hline \multirow[t]{3}{*}{ Three categories of FFLs } & miRNA FFLs & 41 & 27 & 128 & 26 \\
\hline & TF FFLs & 393 & 74 & 218 & 64 \\
\hline & Composite FFLs & 15 & 12 & 104 & 11 \\
\hline
\end{tabular}

in an animal disease model [64]. Such experimental data support the relevance of the constructed miRNA-gene network.

Using ChIPBase, a total of 422 miRNA $\rightarrow$ TF pairs were identified and consisted of 89 CFTR-specific miRNAs and 52 human TFs. Among the 422 miRNA $\rightarrow$ TF pairs, hsamiR-27a was involved in the regulation of 14 TFs. Meanwhile, the genes BCL11A, SMAD2/3, and SMAD4 were regulated by the largest number $(\mathrm{n}=30)$ of miRNAs. Note, reduced SMAD3 protein expression and altered TGF $\beta 1$ mediated signaling in CF epithelial cells were reported [65].

\section{TF-miRNA/gene regulatory networks}

$\mathrm{TF} \rightarrow$ miRNA circuitries were constructed using information retrieved from ChIPBase [46]. A total of 3,295 $\mathrm{TF} \rightarrow$ miRNA combinations were computed and this involved 114 and 102 unique TFs and miRNAs, respectively (see Additional file 3: Table S3). For instance, hsamiR-106b, hsa-miR-25, and hsa-miR-93 were regulated by 72 TFs. Similarly, a total of 16,860 TF-gene pairs were computed and involved $105 \mathrm{TFs}$ and 387 gene targets (see Additional file 3: Table S3). Of the 99 TFs, c-Myc targeted the largest number of CFTR-related genes. It was earlier demonstrated that proteolysis of cMyc in vivo is mediated by the ubiquitin-proteasome pathway [66]. Among the 387 CFTR-related genes, the gene regulated by the largest number of TFs was UBE2D3 (ubiquitin-conjugating enzyme E2 D3). We further searched for common genes among CFTR and 1,042 DEGs and found 38 genes to be mutual.

\section{CFTR-specific feed-forward loops (FFLs)}

It had been demonstrated that composite FFLs (that is, the combined miRNA and TF participating in the regulation of target genes) are more effective in unveiling disease mechanisms than single one as denoted by TF $\rightarrow$ miRNA or miRNA $\rightarrow$ TF considerations [45]. As shown in the third step of Figure 1 and as summarized in Table 2, FFLs were evaluated for their significance using a hypergeometric test with multiple testing corrections. Such analysis revealed 449 unique CFTR-entrained FFLs including 41 miRNA-FFLs, 393 TF-FFLs, and 15 composite-FFLs, as shown in Additional file 3: Table S3. The results indicated that the constructed composite-FFLs were of largest relevance followed by miRNA-FFLs and TFFFLs. Therefore, and based on statistical significance the 15 composite FFLs were employed to search for repurposing candidates for the treatment of CF (Additional file 4: Figure S1). These FFLs contained 12 miRNAs, 11 TFs, and 104 CFTR-related genes, respectively.

We further considered the results of the Kyoto Encyclopedia of Genes and Genomes (KEGG) pathway analysis for the commonly targeted genes of the 15 composite-FFLs. Some composites FFLs, such as hsa$m i R-192 \leftrightarrow \mathrm{CTCF}$ and $h s a-m i R-191 \leftrightarrow \mathrm{TCF} 7 \mathrm{~L} 2$, just have one gene in common; thus no enriched pathways were obtained. As depicted in Additional file 5: Figure S2, 24 different pathways belonging to 13 different functional categories were considered. Among them, two pathways, ubiquitin-mediated proteolysis and protein processing in the endoplasmic reticulum, dominated the composite FFLs, whose major function is folding, sorting, and degradation and these are key mechanism in CF [67]. Other FFLs are involved in insulin and TGF-beta signaling pathways and endocytosis. For instance, CF-related diabetes (CFRD) is a common complication of CF and insulin resistance may also affect lung function [68]. Likewise, transforming growth factor-beta (TGF-beta) plays a central role in fibrosis, contributing to the influx and activation of inflammatory cells, the epithelial to mesenchymal transdifferentiation (EMT) of cells, and the activation of fibroblasts and modulation of extracellular matrix production [69]. Downregulation of CFTR by TGF-beta limits epithelial chloride secretion, which causes mucus block [70]. It was also reported that CF is associated with a defect in apical receptor-mediated endocytosis [71].

\section{Validation of FFLs in CF patient samples}

To determine disease relevance of the FFLs and to study protein-protein-interactions (PPI) among members of the composite FFLs the following data were considered: 
(1) whole genome gene expression data; and (2) miRNA profiling studies using samples obtained from bronchial brushings or nasal epithelium as well as rectal epithelia of CF patients with mild and severe disease and non-CF individuals.

Initially, a total of 123 CFTR genes were retrieved from the study of Ramachandran et al. and for 80 genes a total of 135 PPIs were observed in STRING network analysis. This demonstrates that the network partners actually interact with each other. Moreover, for seven and nine disease-regulated miRNAs and TFs, respectively, a total of 97 PPIs among 66 regulated genes were observed further evidencing interactions among the predicted targets (see Figure 3).

Subsequently, we considered disease regulated miRNA and its directionality based on CF patient samples and therefore analyzed the data of Oglesby et al. [40] and Bhattacharyya et al. [41] with respect to the composite FFLs. This revealed a total of seven miRNAs (hsa-miR26b, hsa-miR-29c, hsa-miR-135b, hsa-miR-155, hsa-miR192, hsa-miR-200c, and hsa-miR-340) and nine FFLs to be CF associated. Note, in the case of miR-155 three different TFs are involved, that is, SP1, NFKB1, and EBF1, therefore giving rise to three distinct diseaserelevant FFLs. We considered miRNAs whose expression was either increased or decreased in CF patient samples (see Figure 4). In order to predict targets of disease associated FFLs we employed a consensus approach using 10 different algorithms (see Additional file 6: Figure S3). The predicted gene targets were considered positive only when confirmed by at least eight different algorithms. Apart from disease specific miRNAs that were used to construct FFLs the regulation of target genes was also considered in CF patient samples. As described above we compiled a total of 1,042 DEGs derived from GEO submissions GSE2395, GSE55146, and GSE15568, and observed DEGs to be commonly regulated in CF samples and disease-specific FFLs, once again providing evidence for the clinical relevance (see Figure 5).

\section{Repurposing candidates for the treatment of CF}

Drug repositioning is a process of identifying alternative indications for existing drugs with acceptable safety at affordable price. To identify drugs with potential use in

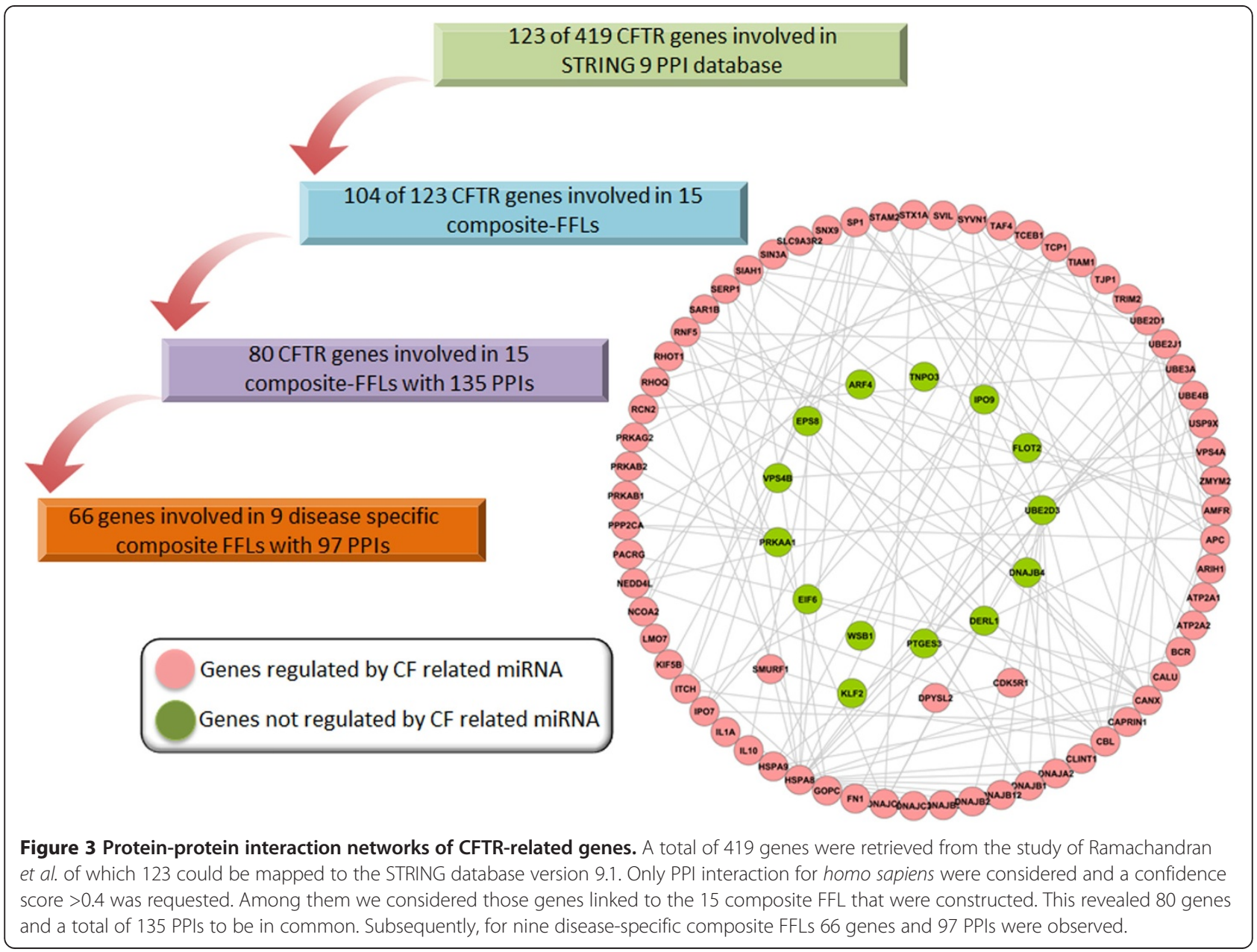




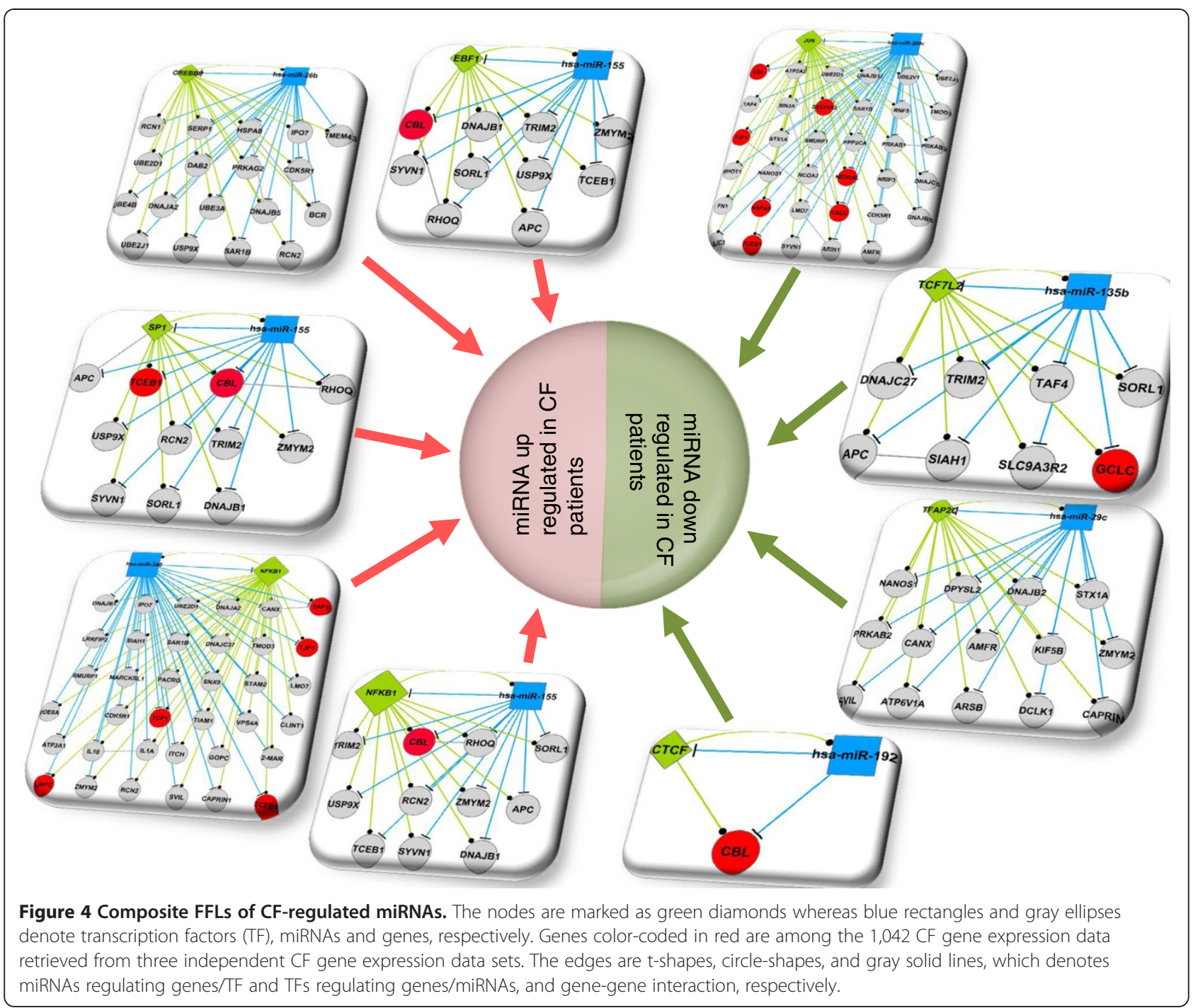

the treatment of CF patients, we exploited small molecules that affect the expression of miRNA which are part of the composite FFLs. We retrieved data from two databases (that is, SM2miR and Pharmaco-miR) as described in Figure 1. Notably, the SM2miR compiles a list of small molecules that interact with miRNAs from the literatures while Pharmaco-miR provides the drug-miRNA association based on the PharmGKB data [72]. We then compared the marketed drug list from DrugBank (version 3.0, [73]) with those identified by SM2miR and Pharmaco-miR as having an ability to influence the expression of miRNA which are part of the FFLs. This process identified 48 unique drugs being strongly designated as repurposing candidates for the treatment of $\mathrm{CF}$ patients.

To assess the validity of the CF repurposing candidates, we conducted a two-step analysis. First, we queried clinicaltrials.gov (www.clinicaltrials.gov) that archives clinical studies of human subjects conducted around the world. Collectively, Table 3 compiles all 48 repurposing candidates for $\mathrm{CF}$ along with their original indications and literature/clinical trial data. Note that eight out of 48 drugs were already investigated for the treatment of $\mathrm{CF}$ patients. For the remaining drug candidates we additionally queried PubMed using the keyword ('drug name' (and) 'cystic fibrosis') followed by reading. Here, 18 out of 43 repurposing candidates have literature citations to support their potential use in CF. Collectively, we found $54.2 \%$ of the candidates ( 26 drugs out of 48 repurposing candidates) to have at least one published study or clinical trial related to CF. Additional file 7: Table S4 lists the information of all 48 repurposing candidates related to drug safety and affordability that were obtained from the FDA-approved drug product labels and the DrugBank V3.0 database.

We further assessed the therapeutic indications of the repurposing candidates and found two categories, that is, Alimentary tract and metabolism $(P<0.0016)$ and 


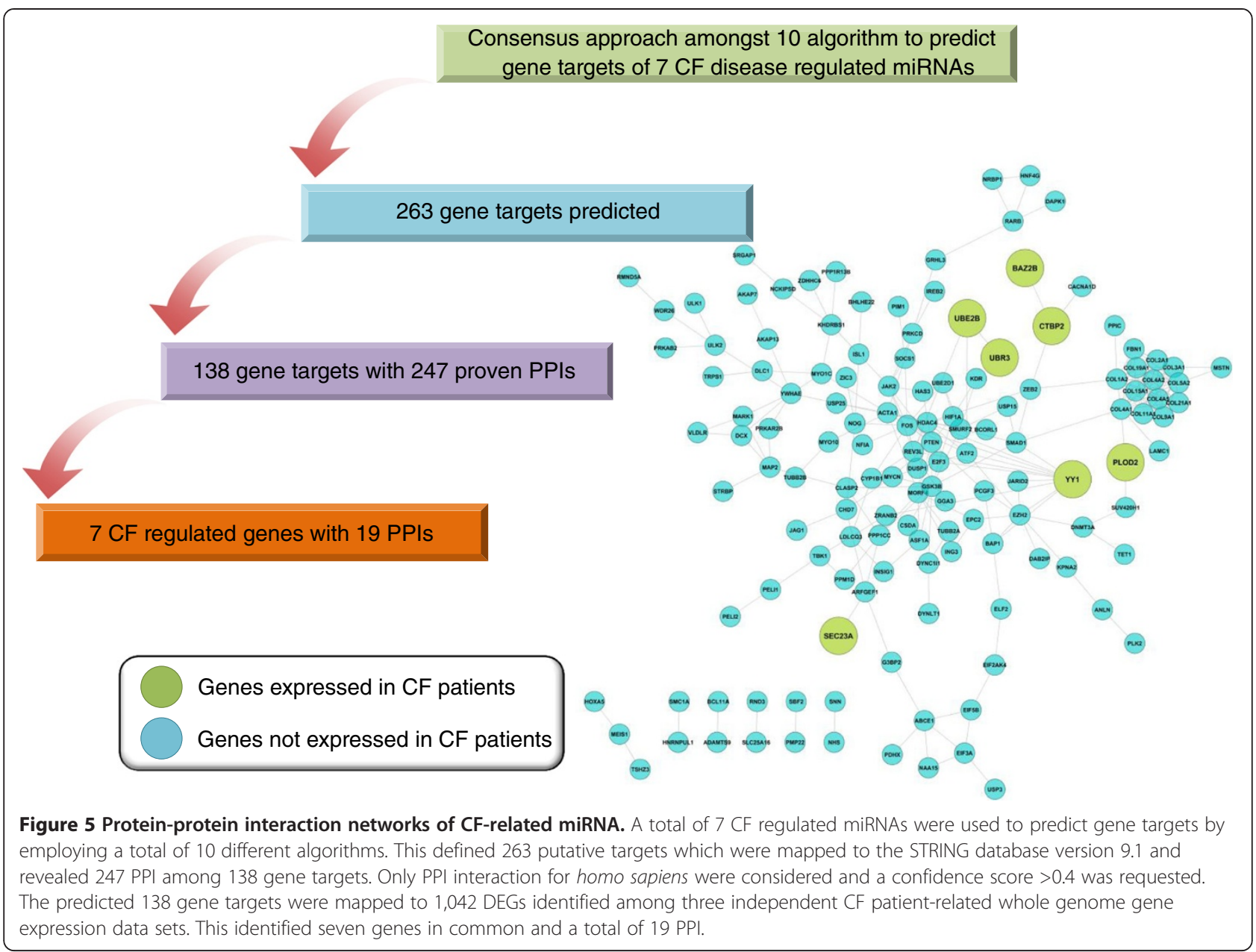

Antineoplastic and immunomodulating agents $(P<0.0009)$ to be significantly enriched. For the different therapeutic categories of the 48 drug repurposing candidates see Figure 6 . Note that the two therapeutic categories include some drugs with boxed warning that need to be considered.

\section{Discussions}

This study aimed to define suitable drug repurposing candidates for the treatment of CF. For this purpose, FFLs were entrained on CFTR and CF gene networks. Applying FFLs to an entire drug landscape is a complex undertaking and next to safety, affordability was considered. In all 41 miRNA-FFLs, 393 TF-FFLs, and 15 composite FFLs were computed. Using diverse computational strategies gene targets were predicted based on disease-regulated miRNA and involved a consensus approach among different algorithms (see Additional file 6: Figure S3). Validation was achieved with CF patient sample-specific information and FFLs were used to enrich the repurposing drug candidate pipeline by considering small molecules effects on miRNA expression. Eventually, 48 repurposing candidates were obtained; their usefulness was considered based on clinical trial information, literature findings, safety concerns, and affordability points of view.

Based on its ability to influence miR-26b [74] and the transcription factor CREBBP [75], dexamethasone was considered as a repurposing candidate. Dexamethasone is a potent steroid and acts as an anti-inflammatory and immunosuppressant. Its use in CF patients is consistent with the current practice of glucocorticoids in the treatment of lung inflammation [76]. It was reported that low doses of dexamethasone delivered by autologous erythrocytes slows the progression of lung disease in CF patients [77]. As dexamethasone is an approved prescription drug without boxed warning, it provides additional value for its application in CF.

The employed testing strategy also predicted statins as interesting repurposing candidate and it was reported that statins retain ceramide levels normal in CF patients $[78,79]$. As ceramides and sphingolipids are components of lipid rafts, they play deceive roles in transmembrane signaling [80]. We found simvastatin to be implicated in the $h s a-m i R-200 c \leftrightarrow J U N$ regulatory FFL. However, some statins are associated with severe adverse drug reactions, 
Table 3 Summary information of 48 repurposing candidates for cystic fibrosis (CF) treatment

\begin{tabular}{llc}
\hline $\begin{array}{l}\text { Repurposing } \quad \text { Original indications } \\
\text { candidates }\end{array}$ & Notes & $\begin{array}{l}\text { Confirmation } \\
\text { sources }\end{array}$ \\
\hline Evidence found from clinic trials (clinicaltrials.gov) &
\end{tabular}

Evidence found from clinic trials (clinicaltrials.gov)

\begin{tabular}{lll}
\hline Simvastatin & Hypercholesterolemia; lower cholesterol & Simvastatin will increase nitric oxide (NO) produced \\
& (exhaled NO), and may decrease airway inflammation
\end{tabular}

Pyruvic acid Dietary shortage or imbalance

The inhalation of sodium pyruvate may reduce lung NCT00308243 damage in patients with CF by its ability to reduce levels of toxic reactive oxygen and nitrogen compounds associated with the chronic inflammatory component of the disease

$\begin{array}{ll}\text { Pioglitazone } & \text { Type } 2 \text { diabetes } \\ \text { I-Glutamine } & \text { Dietary shortage or imbalance }\end{array}$

Desipramine Neuropathic pain; attention deficit hyperactivity disorder; anxiety disorders

Nitric oxide

Neonates with hypoxic respiratory failure

Choline Dietary shortage or imbalance

I-Leucine Prevention of the breakdown of muscle proteins
Pioglitazone may decrease inflammation in CF lung disease

Patients with CF develop frequent and potentially life-threatening lung infections. The nutrient glutamine may help the body fight off infection

Combination of desipramine and VX-770 for CF treatment

Exhaled nitric oxide (NO), elevated in most inflammatory lung diseases, is decreased in CF, suggesting decreased formation, increased metabolism or loss of NO

Nutrition and methyl status of children with CF could be improved after supplying a choline supplement

A high-leucine essential amino acids mixture specifically designed to stimulate protein anabolism could target the metabolic alterations of pediatric subjects with CF

\begin{tabular}{ll}
\hline Literature support & \\
\hline Fluoxetine & Depression; obsessive-compulsive disorder; antiviral \\
& \\
Cyclosporine & $\begin{array}{l}\text { Transplant rejection; rheumatoid arthritis; severe } \\
\text { psoriasis }\end{array}$ \\
Morphine & $\begin{array}{l}\text { Severe pain } \\
\text { Methotrexate }\end{array}$ \\
& $\begin{array}{l}\text { Gestational choriocarcinoma; chorioadenoma } \\
\text { destruens; hydatidiform mole; psoriasis; rheumatoid } \\
\text { arthritis }\end{array}$
\end{tabular}

Vitamin C

Used to treat vitamin C deficiency, scurvy, delayed wound and bone healing, urine acidification, and in general as an antioxidant. It has also been suggested to be an effective antiviral agent

Dexamethasone

I-Arginine

Treating dietary shortage or imbalance

Tacrolimus

Atopic dermatitis; organ rejection

Tamoxifen

Breast cancer
It was suggested that a hydrophobic interaction with high affinity between uncharged fluoxetine and volume-activated chloride channels. $\mathrm{Ca}^{2+}$-activated $\mathrm{Cl}^{-}$currents and CFTR are also blocked by fluoxetine, revealing a novel characteristic of the drug as a chloride channel modulator

PMID:

10077245

15982933

NCT01070446

NCT01172301

(1)
These results suggest that cyclosporine can be beneficial as a steroid sparing agent in CF patients

Inhaled morphine to relieve dyspnea in patients with end-stage lung disease due to CF

It was suggested an effective systemic antiinflammatory effect of methotrexate in treatment for CF patients with advanced pulmonary disease

The pool of vitamin C in the respiratory tract represents a potential nutraceutical and pharmaceutical target for the complementary treatment of sticky airway secretions by enhancing epithelial fluid secretion

Low doses of dexamethasone constantly delivered by autologous erythrocytes slow the progression of lung disease in CF patients

It was suggested that airway nitric oxide formation in CF patients can be augmented with oral L-arginine supplementation

Tacrolimus was tested on lung transplantation of CF patients

PMID:

11213776

PMID:

10973044

PMID:

12735666

PMID:

14993613

PMID:

15223012

PMID:

15640324

PMID:

16372829

This inhibition of $\mathrm{Ca}^{2+}$ signaling was prevented and even potentiated by estrogen antagonists such as tamoxifen, suggesting that antiestrogens may be beneficial in the treatment of CF lung disease because they increase $\mathrm{Cl}^{-}$secretion in the airways
PMID:

19033671 


\section{Table 3 Summary information of 48 repurposing candidates for cystic fibrosis (CF) treatment (Continued)}

\begin{tabular}{|c|c|c|c|}
\hline Rosiglitazone & Type 2 diabetes & $\begin{array}{l}\text { It was suggested rosiglitazone as important modulators } \\
\text { of intestinal } \mathrm{Cl} \text { - secretory function }\end{array}$ & $\begin{array}{l}\text { PMID: } \\
19443733\end{array}$ \\
\hline Vorinostat & Cutaneous T cell lymphoma & $\begin{array}{l}\text { Vorinostat (SAHA) could restore surface channel activity } \\
\text { in human primary airway epithelia to levels that are } \\
28 \% \text { of those of wild-type CFTR }\end{array}$ & $\begin{array}{l}\text { PMID: } \\
19966789\end{array}$ \\
\hline Metformin & $\begin{array}{l}\text { Type } 2 \text { diabetes; prediabetes; polycystic ovary } \\
\text { syndrome; gestational diabetes }\end{array}$ & $\begin{array}{l}\text { The metabolic sensor AMP-activated kinase (AMPK) } \\
\text { inhibits both the CFTR CI(-) channel and epithelial } \\
\mathrm{Na}(+) \text { channel (ENaC), and may inhibit secretion of } \\
\text { proinflammatory cytokines in epithelia }\end{array}$ & $\begin{array}{l}\text { PMID: } \\
19617399\end{array}$ \\
\hline Estradiol & Urogenital & $\begin{array}{l}\text { 17Beta-estradiol inhibits IL-8 release by ERbeta in CF } \\
\text { bronchial epithelial cells through upregulation of } \\
\text { secretory leucoprotease inhibitor, inhibition of nuclear } \\
\text { factor (NF)-kappaB, and IL-8 gene expression. These } \\
\text { data implicate a novel anti-inflammatory mechanism } \\
\text { for E(2) in females with CF, which predisposes to } \\
\text { infection and colonization }\end{array}$ & $\begin{array}{l}\text { PMID: } \\
20378727\end{array}$ \\
\hline Chloroquine & Malaria; strains of P. falciparum; rheumatoid arthritis & $\begin{array}{l}\text { Vasculitis is a well recognized complication of CF. There } \\
\text { is a case of steroid-resistant cutaneous vasculitis which } \\
\text { was successfully treated with chloroquine in addition } \\
\text { to corticosteroids and a subsequent relapse with } \\
\text { chloroquine alone }\end{array}$ & $\begin{array}{l}\text { PMID: } \\
20863769\end{array}$ \\
\hline Sirolimus & Prophylaxis & $\begin{array}{l}\text { Autophagy stimulation by sirolimus (rapamycin) } \\
\text { suppresses lung inflammation and infection by } \\
\text { Burkholderia cenocepacia in a model of CF }\end{array}$ & $\begin{array}{l}\text { PMID: } \\
21997369\end{array}$ \\
\hline Nifedipine & $\begin{array}{l}\text { Vasospastic angina; chronic stable angina; } \\
\text { hypertension; Raynaud's phenomenon }\end{array}$ & $\begin{array}{l}\text { Nifedipine may be a useful adjuvant to supplemental } \\
\text { oxygen in the treatment of patients with CF and cor } \\
\text { pulmonale }\end{array}$ & $\begin{array}{l}\text { PMID: } \\
6476600\end{array}$ \\
\hline Levamisole & Dukes' stage C colon cancer; worm infestations & $\begin{array}{l}\text { Levamisole could block } \mathrm{K}+\text { channels required for } \mathrm{Cl} \\
(-) \text {-secretory responses elicited by diverse pathways in } \\
\text { model epithelia and native colon, an effect that } \\
\text { outweighs their ability to activate apical Cl- channels }\end{array}$ & $\begin{array}{l}\text { PMID: } \\
9609763\end{array}$ \\
\hline
\end{tabular}

\section{Potential candidates for CF treatment}

\begin{tabular}{ll}
\hline Imiquimod & $\begin{array}{l}\text { non-hyperkeratotic; non-hypertrophic actinic } \\
\text { keratoses }\end{array}$ \\
Phenobarbital & Seizures \\
Leucovorin & Osteosarcoma \\
Imatinib & Philadelphia chromosome positive chronic myeloid \\
& leukemia (CML); malignant gastrointestinal stromal \\
& tumors (GIST) \\
Gemcitabine & Metastatic breast cancer \\
Dienestrol & Atrophic vaginitis; kraurosis vulvae \\
Cyclophosphamide & Malignant lymphomas; multiple myeloma; \\
Chlorotrianisene & $\begin{array}{l}\text { Meukemias } \\
\text { Amiodarone }\end{array}$ \\
Cardiac dysrhythmias \\
Rarfarin
\end{tabular}


Table 3 Summary information of $\mathbf{4 8}$ repurposing candidates for cystic fibrosis (CF) treatment (Continued)

\begin{tabular}{|c|c|}
\hline Paclitaxel & $\begin{array}{l}\text { Kaposi's sarcoma; cancer of the lung; ovarian and } \\
\text { breast }\end{array}$ \\
\hline Oxaliplatin & Cancer chemotherapy \\
\hline Imipramine & Depression \\
\hline Fluorouracil & Multiple actinic; solar keratoses \\
\hline Mercaptopurine & Acute lymphatic leukemia \\
\hline Cetuximab & $\begin{array}{l}\text { EGFR-expressing metastatic colorectal cancer; } \\
\text { squamous cell carcinoma }\end{array}$ \\
\hline Dopamine & Hemodynamic imbalances \\
\hline Vinblastine & $\begin{array}{l}\text { Breast cancer; Hodgkin's and non-Hodgkin's } \\
\text { lymphomas; Kaposi's sarcoma }\end{array}$ \\
\hline $\begin{array}{l}\text { Adenosine } \\
\text { monophosphate }\end{array}$ & Dietary shortage or imbalance \\
\hline
\end{tabular}

most notable rhabdomyolysis. For this reason cerivastatin had been withdrawn from the market [81]. In a clinical trial (NCT00255242) the beneficial effect of simvastatin in alleviating airway inflammation in CF patients was investigated [82] and statins without boxed warning in the label are interesting repurposing candidates.
Likewise, phenylimidazothiazoles were reported to activate wild-type and mutant CFTR in transfected cells and thus, have been proposed as drug remedy for CF $[83,84]$. The present study inferred levamisole to perturb the $h s a-m i r-26 b \leftrightarrow C R E B B P$ and $h s a-m i R-200 c \leftrightarrow J U N$ FFLs and this drug was used to treat Dukes' stage $C$

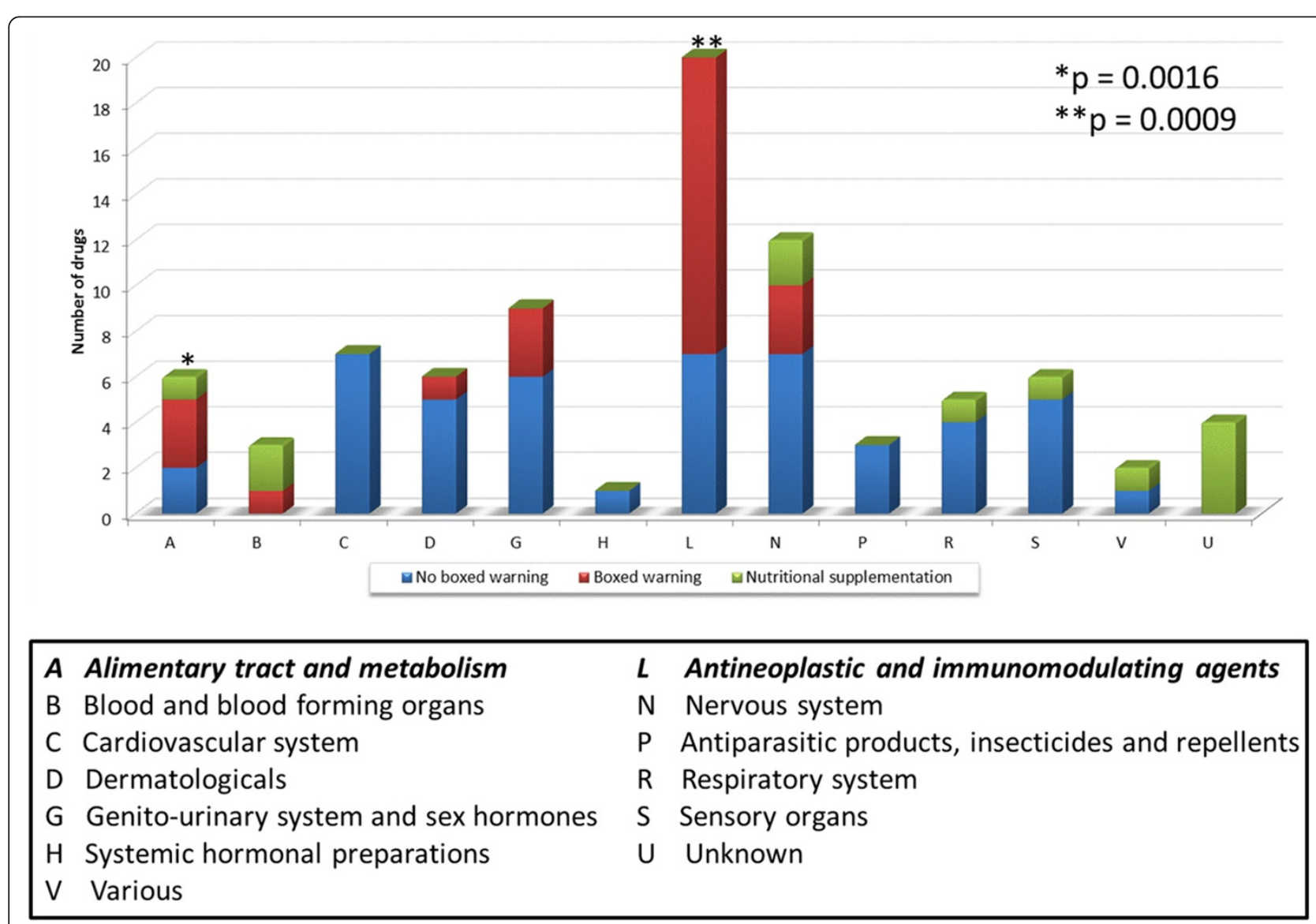

Figure 6 The distribution of repurposing candidates for CF at the first level of Anatomical Therapeutic Chemical Classification System (ATC). Each bar was divided by safety concerns including boxed warning, no boxed warning, and nutritional supplementation. The statistical significance of the therapeutic categories associated with CF are A and L based on the Fisher's exact test with a $P$ value cutoff of 0.01 . 
colon cancer and worm infestations. It was demonstrated that levamisole inhibited intestinal $\mathrm{Cl}^{-}$transport via basolateral $\mathrm{K}^{+}$channel blockade [85] and this provides a molecular rational for further evaluation.

In another clinical trial (NCT01070446), the effects of choline supplementation in children with CF was investigated. Note, children with CF are reported to have depleted levels of choline [86] and choline is involved in two composite FFLs including $h s a-m i R-200 c \leftrightarrow J U N$ and has-miR-29c↔TFAP2C as per our investigations.

Furthermore, among the repositioning candidates were thiazolidinediones (TZD), which were initially used to treat type-II diabetes. This class of drugs includes both pioglitazone and rosiglitazone. Some evidence exists that TZD could be used to ameliorate the severity of the CF phenotype [87]. Pioglitazone and rosiglitazone are known to activate peroxisome proliferator-activated receptor gamma (PPAR $\gamma$ ) and it has been suggested that a reversible defect in PPAR $\gamma$ signaling in Cftr-deficient cells could improve the severity of the CF phenotype in mice. Additionally, in clinical trial NCT00322868 pioglitazone was evaluated for its ability to decrease inflammation in CF lung patients. While thiazolidinediones are promising, unfortunately this class of drug has been reported to exacerbate congestive heart failure in some patients and thus are labelled with a boxed warning. In addition, troglitazone was withdrawn from the market due to severe liver toxicity [88].

The performed analysis also identified some anti-cancer drugs for potential use in CF patients $[89,90]$ and it was hypothesized that induction of homologous recombination in respiratory epithelium helps to improve the lung function of patients [90]. In our analysis, vorinostat (SAHA), a histone-deacetylase inhibitor and anti-cancer drug used to treat cutaneous T-cell lymphoma, appeared to be a reasonable repurposing candidate. This drug was reported to restore surface channel activity in human primary airway epithelia to a level that was $28 \%$ of wild-type CFTR and does not have a boxed warning, but is fairly expensive.

The developed drug repurposing strategy is a modular system and each of the components can be modified or even replaced by other algorithms. Besides TargetScan there are alternatives approaches such as RNAhybrid [56], DIANAmicroT [52], RNA22 [59], miRanda [53], PicTar [57], and miRWalk [55] to predict gene targets. Indeed, it has been suggested that combining diverse algorithms could provide more confidence in the inferred drug miRNA-gene relationships $[20,91]$. To this effect we employed a consensus approach for predicting gene targets of disease-regulated miRNAs by using 10 different algorithms. Lastly, the directions of the disease-regulated miRNAs were considered and the consensus approach revealed that $48 \%$ of the predicted targets by TargetScan could be confirmed by at least another algorithm. Moreover, for the TF binding site predictions, we utilized experimental data retrieved from ChIP-Seq experiments. Other technologies such as CHIP on chip array or in silico approaches based on position weight matrices can also be employed to identify putative transcription factor binding sites [92].

The present study focused on repurposing candidates from the miRNA-small molecule perspective while the relationship between TFs and small molecules, that is, drugs affecting transcription factor expression and activity was not considered in detail. So far only a few drugs target TF and would therefore limit the choice of drug repurposing candidates; nonetheless drugs targeting TFs will increase with time [93]. A recent study demonstrated heat shock transcription factor 1 (HSF1) as a potential new therapeutic target in multiple myeloma [94] and other studies revealed that nuclear transcription factor-kappa B $(N F \kappa B)$ could be a potential target for drug development in different disease entities [95-97]. We also found $N F K B$ to be involved in several composite-FFLs including has-miR-155↔NFKB and has$m i R-340 \leftrightarrow N F \kappa B$. Note that ibuprofen, a non-steroidal anti-inflammatory drug (NSAID), is one of the antiinflammatory therapies used in the treatment of CF $[98,99]$. It has been demonstrated that high dose ibuprofen causes modest suppression of $N F K B$ transcriptional activity in CF respiratory epithelial cells. Furthermore, $m i R-155$ promotes inflammation in CF by driving hyperexpression of interleukin-8 [41]. In future studies, the transcription factor drug relationship will be explored in greater detail.

The goal of drug repurposing is to bring new therapies to the market at a lower risk, reduced cost, and less development time when compared to conventional drug development programs [100]. However, the safety assessment in a new disease indication is still an important concern in the regulatory process. While the safety assessment is based on drug label information, the drug repositioning approach may involve different formulations and changes in dosage that need to be considered in different patient populations. For instance, the use of high dose ibuprofen in $\mathrm{CF}$ is concerning for its adverse drug reactions, most notably in causing GI hemorrhage, myocardial infarction, drug-induced liver injury, and even renal failure [7]. Additional approaches for safety assessment of market drugs are the U.S. FDA Adverse Event Reporting System (FAERS) [101] and the FDA's Sentinel initiative [102]. Finally, $10 \%$ of healthcare expenditure in the U.S. has been attributed to prescribed drugs [103]. Thus, drug affordability will require consideration.

\section{Conclusion}

In conclusion, we report a strategy for the rational selection of drug repurposing candidates based on miRNATF FFLs. The methodology developed is straightforward 
and may also apply for the selection of drug candidates in other rare diseases.

\section{Additional files}

Additional file 1: Table S1. Cystic fibrosis related genes from diverse of

Additional file 2: Table S2. CFTR associated miRNAs.

Additional file 3: Table S3. The enriched cystic fibrosis related feed forward loops (FFLs).

Additional file 4: Figure S1. The composite feed-forward loops (FFLs) for CF. The nodes are green diamonds, blue rectangles, and gray ellipses which denote transcription factors (TFs), miRNAs, and genes, respectively. The edges are t-shapes, circle-shapes, and gray solid lines, which represent repression of miRNAs to genes/TF, regulation of TFs to genes/miRNAs, and gene-gene interaction, respectively.

Additional file 5: Figure S2. Network of composite-FFLs and enriched KEGG pathway based on the common targeted genes of the composite-FFLs. The KEGG pathways are tested for statistical significance by using the Fisher's exact test with multiple testing corrections. Only the pathways with corrected $P$ values less than 0.05 were considered enriched.

Additional file 6: Figure S3. Comparsion of miRNA target predictions for miRNAs involved in 15 composite FFLs based on 10 different algorithms.

Additional file 7: Table S4. The information of 48 enriched candidates for cystic fibrosis

\section{Competing interests}

The authors have declared that they have no competing interests.

\section{Authors' contributions}

Conceived and designed the experiments: $Z \mathrm{~L}, \mathrm{JB}, \mathrm{WT}$. Performed the experiments: ZL. Analyzed the data: ZL. Contributed reagents/materials/ analysis tools: ZL, JB, and WT. Wrote the manuscript: ZL, JB, and WT. All authors read and approved the final manuscript.

\section{Authors' information}

JB and WT are senior authors.

\section{Funding}

JB receives funding from the German Federal Ministry for Education and Research as part of the Virtual Liver Network initiative (Grant number 031 6154). Furthermore, JB is recipient of an ORISE Stipend of the FDA which is gratefully acknowledged.

\section{Disclaimer}

The views presented in this article do not necessarily reflect current or future opinion or policy of the US Food and Drug Administration. Any mention of commercial products is for clarification and not intended as endorsement.

Received: 12 August 2014 Accepted: 23 October 2014

Published online: 02 December 2014

\section{References}

1. Cohen TS, Prince A: Cystic fibrosis: a mucosal immunodeficiency syndrome. Nat Med 2012, 18:509-519.

2. Storey S, Wald G: Novel agents in cystic fibrosis. Nat Rev Drug Discov 2008, 7:555-556.

3. Drug bests cystic-fibrosis mutation. [http://www.nature.com/news/drugbests-cystic-fibrosis-mutation-1.9983]

4. Are we entering the age of the $\$ 1$ million medicine? [http://www. foxnews.com/health/2013/01/03/are-entering-age-1-million-medicine/]

5. Sardana D, Zhu C, Zhang M, Gudivada RC, Yang L, Jegga AG: Drug repositioning for orphan diseases. Brief Bioinform 2011, 12:346-356.

6. Ekins S, Williams AJ, Krasowski MD, Freundlich JS: In silico repositioning of approved drugs for rare and neglected diseases. Drug Discov Today 2011 , 16:298-310.
7. Chmiel JF, Konstan MW: Inflammation and anti-inflammatory therapies for cystic fibrosis. Clin Chest Med 2007, 28:331-346.

8. Kraynack NC, Corey DA, Elmer HL, Kelley TJ: Mechanisms of NOS2 regulation by Rho GTPase signaling in airway epithelial cells. Am J Physio Lung Cell Mol Physiol 2002, 283:L604-L611

9. BalfourLynn IM, Laverty A, Dinwiddie R: Reduced upper airway nitric oxide in cystic fibrosis. Arch Dis Child 1996, 75:319-322.

10. Kharitonov SA, Yates D, Robbins RA, Logansinclair R, Shinebourne EA, Barnes PJ: Increased nitric oxide in exhaled air of asthmatic patients. Lancet 1994, 343:133-135.

11. Milo R, Shen-Orr S, Itzkovitz S, Kashtan N, Chklovskii D, Alon U: Network motifs: simple building blocks of complex networks. Science 2002, 298:824-827.

12. Hall JC, Rosen A: Type I interferons: crucial participants in disease amplification in autoimmunity. Nat Rev Rheumatol 2010, 6:40-49.

13. Taylor RC, Acquaah-Mensah G, Singhal M, Malhotra D, Biswal S: Network inference algorithms elucidate Nrf2 regulation of mouse lung oxidative stress. PLoS Comput Biol 2008, 4:e1000166.

14. Guo A-Y, Sun J, Jia P, Zhao Z: A Novel microRNA and transcription factor mediated regulatory network in schizophrenia. BMC Syst Biol 2010, 4:10.

15. Afshar AS, Xu J, Goutsias J: Integrative Identification of Deregulated MiRNA/TF-Mediated Gene Regulatory Loops and Networks in Prostate Cancer. PLOS ONE 2014, 9:e100806.

16. Chen K, Rajewsky N: The evolution of gene regulation by transcription factors and microRNAs. Nat Rev Genet 2007, 8:93-103.

17. Stefani G, Slack FJ: Small non-coding RNAs in animal development. Nat Rev Mol Cell Biol 2008, 9:219-230.

18. Esquela-Kerscher A, Slack FJ: Oncomirs - microRNAs with a role in cancer. Nat Rev Cancer 2006, 6:259-269.

19. Volinia S, Calin GA, Liu C-G, Ambs S, Cimmino A, Petrocca F, Visone R, lorio M, Roldo C, Ferracin M, Prueitt RL, Yanaihara N, Lanza G, Scarpa A, Vecchione A, Negrini M, Harris CC, Croce CM: A microRNA expression signature of human solid tumors defines cancer gene targets. Proc Natl Acad Sci U S A 2006, 103:2257-2261.

20. Angerstein C, Hecker M, Paap BK, Koczan D, Thamilarasan M, Thiesen HJ, Zettl UK: Integration of microRNA databases to study microRNAs associated with multiple sclerosis. Mol Neurobiol 2012, 45:520-535.

21. Ling HY, Ou HS, Feng SD, Zhang XY, Tuo QH, Chen LX, Zhu BY, Gao ZP, Tang CK, Yin WD, Zhang L, Liao DF: CHANGES IN microRNA (miR) profile and effects of miR-320 in insulin-resistant 3 T3-L1 adipocytes. Clin Exp Pharmacol Physiol 2009, 36:e32-e39.

22. Wang K, Zhang S, Marzolf B, Troisch P, Brightman A, Hu Z: Hood LE. Circulating microRNAs, potential biomarkers for drug-induced liver injury. Proc Natl Acad Sci: Galas DJ; 2009.

23. Cheng $Y$, Zhang C: MicroRNA-21 in cardiovascular disease. J CardiovasC Trans/ Res 2010, 3:251-255.

24. Hassan F, Nuovo GJ, Crawford M, Boyaka PN, Kirkby S, Nana-Sinkam SP Cormet-Boyaka E: MiR-101 and miR-144 regulate the expression of the CFTR chloride channel in the lung. PLoS One 2012, 7:e50837.

25. Ramachandran S, Karp PH, Jiang P, Ostedgaard LS, Walz AE, Fisher JT, Keshavjee S, Lennox KA, Jacobi AM, Rose SD, Behlke MA, Welsh MJ, Xing Y, McCray PB Jr: A microRNA network regulates expression and biosynthesis of wild-type and Delta F508 mutant cystic fibrosis transmembrane conductance regulator. Proc Natl Acad Sci U S A 2012, 109:13362-13367.

26. Megiorni F, Cialfi S, Dominici C, Quattrucci S, Pizzuti A: Synergistic posttranscriptional regulation of the Cystic Fibrosis Transmembrane conductance Regulator (CFTR) by miR-101 and miR-494 specific binding. PLoS One 2011, 6:e26601.

27. Gillen $A E$, Gosalia N, Leir SH: Harris A: microRNA regulation of expression of the cystic fibrosis transmembrane conductance regulator gene. Biochem J 2011, 438:25-32.

28. Xu W, Hui C, Yu SSB, Jing C, Chan HC: MicroRNAs and cystic fibrosis - an epigenetic perspective. Cell Biol Int 2011, 35:463-466.

29. Collison A, Herbert C, Siegle J, Mattes J, Foster P, Kumar R: Altered expression of microRNA in the airway wall in chronic asthma: miR-126 as a potential therapeutic target. BMC Pulmonary Medicine 2011, 11:29.

30. Vaquerizas JM, Kummerfeld SK, Teichmann SA, Luscombe NM: A census of human transcription factors: function, expression and evolution. Nat Rev Genet 2009, 10:252-263.

31. Hobert $\mathrm{O}$ : Gene regulation by transcription factors and microRNAs. Science 2008, 319:1785-1786.

32. Genetic Association Database. [http://geneticassociationdb.nih.gov/] 
33. Becker KG, Barnes KC, Bright TJ, Wang SA: The genetic association database. Nat Genet 2004, 36:431-432.

34. Ayme S, Schmidtke J: Networking for rare diseases: a necessity for Europe. Bundesgesundheitsblatt Gesundheitsforschung Gesundheitsschutz 2007, 50:1477-1483.

35. Orphadata. [http://www.orphadata.org/cgi-bin/index.php]

36. Online Mendelian Inheritance in Man (OMIM). [http://www.omim.org/]

37. McKusick VA: Mendelian inheritance in man and its online version, OMIM Am J Hum Genet 2007, 80:588-604.

38. Functional Disease Ontology Annotations (FunDO). [http://django.nubic. northwestern.edu/fundo/]

39. Schriml LM, Arze C, Nadendla S, Chang YWW, Mazaitis M, Felix V, Feng G, Kibbe WA: Disease Ontology: a backbone for disease semantic integration. Nucleic Acids Res 2012, 40:D940-D946.

40. Oglesby IK, Bray IM, Chotirmall SH, Stallings RL, O' Neill SJ, McElvaney NG, Greene CM: miR-126 Is Downregulated in Cystic Fibrosis Airway Epithelial Cells and Regulates TOM1 Expression. J Immunol 2010, 184:1702-1709.

41. Bhattacharyya S, Balakathiresan NS, Dalgard C, Gutti U, Armistead D, Jozwik C, Srivastava M, Pollard HB, Biswas R: Elevated miR-155 promotes inflammation in cystic fibrosis by driving hyperexpression of interleukin-8. J Biol Chem 2011, 286:11604-11615

42. Lewis BP, Shih IH, Jones-Rhoades MW, Bartel DP, Burge CB: Prediction of mammalian microRNA targets. Cell 2003, 115:787-798.

43. Baek D, Villen J, Shin C, Camargo FD, Gygi SP, Bartel DP: The impact of microRNAs on protein output. Nature 2008, 455:64-U38.

44. Selbach M, Schwanhausser B, Thierfelder N, Fang Z, Khanin R, Rajewsky N: Widespread changes in protein synthesis induced by microRNAs. Nature 2008, 455:58-63.

45. Sun JC, Gong X, Purow B, Zhao ZM: Uncovering microRNA and transcription factor mediated regulatory networks in glioblastoma. PLoS Comput Biol 2012, 8:e1002488.

46. Yang J-H, Li J-H, Jiang S, Zhou H, Qu L-H: ChIPBase: a database for decoding the transcriptional regulation of long non-coding RNA and microRNA genes from ChIP-Seq data. Nucleic Acids Res 2013, 41:D177-187.

47. Barrett T, Troup DB, Wilhite SE, Ledoux P, Evangelista C, Kim IF, Tomashevsky M, Marshall KA, Phillippy KH, Sherman PM, Muertter RN, Holko M, Ayanbule O, Yefanov A, Soboleva A: NCBI GEO: archive for functional genomics data sets-10 years on. Nucleic Acids Res 2011, 39:D1005-D1010.

48. ENCODE Project Consortium: A user's guide to the encyclopedia of DNA elements (ENCODE). PLOS Biol 2011, 9:e1001046.

49. Negre $N$, Brown CD, Ma LJ, Bristow CA, Miller SW, Wagner U, Kheradpour $P$, Eaton ML, Loriaux P, Sealfon R, Li Z, Ishii H, Spokony RF, Chen J, Hwang L, Cheng C, Auburn RP, Davis MB, Domanus M, Shah PK, Morrison CA, Zieba J, Suchy S, Senderowicz L, Victorsen A, Bild NA, Grundstad AJ, Hanley D, MacAlpine DM, Mannervik M, et al: A cis-regulatory map of the Drosophila genome. Nature 2011, 471:527-531.

50. Gerstein MB, Lu ZJ, Van Nostrand EL, Cheng C, Arshinoff Bl, Liu T, Yip KY, Robilotto R, Rechtsteiner A, Ikegami K, Alves P, Chateigner A, Perry M, Morris M, Auerbach RK, Feng X, Leng J, Vielle A, Niu W, Rhrissorrakrai K, Agarwal A, Alexander RP, Barber G, Brdlik CM, Brennan J, Brouillet JJ, Carr A, Cheung MS, Clawson H, Contrino S, et al: Integrative analysis of the Caenorhabditis elegans genome by the modENCODE project. Science 2010, 330:1775-1787.

51. Szklarczyk D, Franceschini A, Kuhn M, Simonovic M, Roth A, Minguez $P$, Doerks T, Stark M, Muller J, Bork P, Jensen LJ, von Mering C: The STRING database in 2011: functional interaction networks of proteins, globally integrated and scored. Nucleic Acids Res 2011, 39:D561-D568.

52. Kiriakidou M, Nelson PT, Kouranov A, Fitziev P, Bouyioukos C, Mourelatos Z, Hatzigeorgiou A: A combined computational-experimental approach predicts human microRNA targets. Genes Dev 2004, 18:1165-1178.

53. Enright A, John B, Gaul U, Tuschl T, Sander C, Marks D: MicroRNA targets in Drosophila. Genome Biol 2003, 5:R1

54. Wang $X$, El Naqa IM: Prediction of both conserved and nonconserved microRNA targets in animals. Bioinformatics 2008, 24:325-332.

55. Dweep H, Sticht C, Pandey P, Gretz N: miRWalk-Database: Prediction of possible miRNA binding sites by "walking" the genes of three genomes. J Biomed Inform 2011, 44:839-847.

56. Rehmsmeier M, Steffen $P$, Hochsmann M, Giegerich R: Fast and effective prediction of microRNA/target duplexes. RNA 2004, 10:1507-1517.

57. Krek A, Grun D, Poy MN, Wolf R, Rosenberg L, Epstein EJ, MacMenamin P da Piedade I, Gunsalus KC, Stoffel M, Rajewsky N: Combinatorial microRNA target predictions. Nat Genet 2005, 37:495-500.
58. Kertesz M, lovino N, Unnerstall U, Gaul U, Segal E: The role of site accessibility in microRNA target recognition. Nat Genet 2007, 39:1278-1284

59. Miranda KC, Huynh T, Tay Y, Ang Y-S, Tam W-L, Thomson AM, Lim B, Rigoutsos I: A pattern-based method for the identification of microRNA binding sites and their corresponding heteroduplexes. Cell 2006, 126:1203-1217.

60. Grimson A, Farh KK-H, Johnston WK, Garrett-Engele P, Lim LP, Bartel DP: MicroRNA targeting specificity in mammals: determinants beyond seed pairing. Mol Cell 2007, 27:91-105.

61. Liu X, Wang S, Meng F, Wang J, Zhang Y, Dai E, Yu X, Li X, Jiang W: SM2miR: a database of the experimentally validated small molecules' effects on microRNA expression. Bioinformatics 2013, 29:409-411.

62. Rukov JL, Wilentzik R, Jaffe I, Vinther J, Shomron N: Pharmaco-miR: linking microRNAs and drug effects. Brief Bioinform 2014, 15:648-659.

63. Kamanu TKK, Radovanovic A, Archer JAC, Bajic VB: Exploration of miRNA families for hypotheses generation. Sci Rep 2013, 3:2940.

64. Kimura T, Kawabe H, Jiang C, Zhang WB, Xiang YY, Lu C, Salter MW, Brose N Lu WY, Rotin D: Deletion of the ubiquitin ligase Nedd4L in lung epithelia causes cystic fibrosis-like disease. Proc Natl Acad Sci U S A 2011, 108:3216-3221.

65. Kelley TJ, Elmer HL, Corey DA: Reduced Smad3 protein expression and altered transforming growth factor-beta 1-mediated signaling in cystic fibrosis epithelial cells. Am J Respir Cell Mol Biol 2001, 25:732-738.

66. Gregory MA, Hann SR: c-Myc proteolysis by the ubiquitin-proteasome pathway: Stabilization of c-Myc in Burkitt's lymphoma cells. Mol Cell Biol 2000, 20:2423-2435.

67. Van Goor F, Hadida S, Grootenhuis PDJ, Burton B, Stack JH, Straley KS, Decker CJ, Miller M, McCartney J, Olson ER, Wine JJ, Frizzell RA, Ashlock M, Negulescu PA: Correction of the F508del-CFTR protein processing defect in vitro by the investigational drug VX-809. Proc Natl Acad Sci 2011, 108:18843-18848.

68. Bridges N: Diabetes in cystic fibrosis. Paediatr Respir Rev 2013, Suppl 1:16-18.

69. Flanders KC: Smad3 as a mediator of the fibrotic response. Int J Exp Pathol 2004, 85:47-64.

70. Howe KL, Wang A, Hunter MM, Stanton BA, McKay DM: TGF beta downregulation of the CFTR: a means to limit epithelial chloride secretion. Exp Cell Res 2004, 298:473-484.

71. Fo J, Bernard A, Hermans C, Dom G, Terryn S, Leal T, Lebecque P, Cassiman $J$-J, Scholte BJ, de Jonge HR, Courtoy PJ, Devuyst O: Cystic fibrosis is associated with a defect in apical receptor-mediated endocytosis in mouse and human kidney. J Am Soc Nephrol 2007, 18:707-718.

72. PharmGKB. [http://www.pharmgkb.org/]

73. DrugBank. [http://www.drugbank.ca/]

74. Smith LK, Shah RR, Cidlowski JA: Glucocorticoids modulate microRNA expression and processing during lymphocyte apoptosis. J Biol Chem 2010, 285:36698-36708.

75. Kino T, Nordeen SK, Chrousos GP: Conditional modulation of glucocorticoid receptor activities by CREB-binding protein (CBP) and p300. J Steroid Biochem Mol Biol 1999, 70:15-25.

76. Rebeyrol C, Saint-Criq V, Guillot LC, Riffault L, Corvol H, Chadelat K, Ray DW, Clement A, Tabary O, Le Rouzic P: Glucocorticoids reduce inflammation in cystic fibrosis bronchial epithelial cells. Cell Signal 2012, 24:1093-1099.

77. Rossi L, Castro M, D’Orio F, Damonte G, Serafini S, Bigi L, Panzani I, Novelli G, Dallapiccola B, Panunzi S, Di Carlo P, Bella S, Magnani M: Low doses of dexamethasone constantly delivered by autologous erythrocytes slow the progression of lung disease in cystic fibrosis patients. Blood Cell Mol Dis 2004, 33:57-63.

78. Teichgraber V, Ulrich M, Endlich N, Riethmuller J, Wilker B, De OliveiraMunding CC, van Heeckeren AM, Barr ML, von Kurthy G, Schmid KW, Weller M, Tummler B, Lang F, Grassme H, Doring G, Gulbins E: Ceramide accumulation mediates inflammation, cell death and infection susceptibility in cystic fibrosis. Nat Med 2008, 14:382-391.

79. Pier GB: Dropping acid to help cystic fibrosis. Nat Med 2008, 14:367-369.

80. Simons K, Toomre D: Lipid rafts and signal transduction. Nat Rev Mol Cell Biol 2000, 1:31-39.

81. Furberg C, Pitt B: Withdrawal of cerivastatin from the world market. Curr Control Trials Cardiovasc Med 2001, 2:205-207.

82. Jones A, Helm J: Emerging treatments in cystic fibrosis. Drugs 2009, 69:1903-1910. 
83. Fdr B, Verrier B, Chang X-B, Riordan JR, Hanrahan JW: CAMP- and Ca2 + -independent activation of cystic fibrosis transmembrane conductance regulator channels by phenylimidazothiazole drugs. J Biol Chem 1996, 271:16171-16179.

84. Becq F, Jensen TJ, Chang XB, Savoia A, Rommens JM, Tsui LC, Buchwald M Riordan JR, Hanrahan JW: Phosphatase inhibitors activate normal and defective CFTR chloride channels. Proc Natl Acad Sci 1994, 91:9160-9164.

85. Mun EC, Mayol JM, Riegler M, O'Brien TC, Farokhzad OC, Song JC, Pothoulakis C, Hrnjez BJ, Matthews JB: Levamisole inhibits intestinal Clâ^’ secretion via basolateral K + channel blockade. Gastroenterology 1998, 114:1257-1267.

86. Innis SM, Davidson AGF, Bay BN, Slack PJ, Hasman D: Plasma choline depletion is associated with decreased peripheral blood leukocyte acetylcholine in children with cystic fibrosis. Am J Clin Nutr 2011, 93:564-568.

87. Harmon GS, Dumlao DS, Ng DT, Barrett KE, Dennis EA, Dong H, Glass CK: Pharmacological correction of a defect in PPAR-[gamma] signaling ameliorates disease severity in Cftr-deficient mice. Nat Med 2010, 16:313-318.

88. Henney JE: Withdrawal of troglitazone and cisapride. JAMA 2000, 283:2228.

89. Faivre $L$, Bonnefont JP, Lyonnet S, Munnich A, Vekemans M: Improvement of cystic fibrosis using antitumoral drugs: a hypothesis. Med Hypotheses 2000, 54:580-581.

90. Lallemand JY, Stoven V, Annereau JP, Boucher J, Blanquet S, Barthe J, Lenoir G: Induction by antitumoral drugs of proteins that functionally complement CFTR: a novel therapy for cystic fibrosis? Lancet 1997, 350:711-712.

91. Jiang W, Chen X, Liao M, Li W, Lian B, Wang L, Meng F, Liu X, Chen X, Jin Y, Li X: Identification of links between small molecules and miRNAs in human cancers based on transcriptional responses. Sci Rep 2012, 2:282.

92. Matys V, Kel-Margoulis OV, Fricke E, Liebich I, Land S, Barre-Dirrie A, Reuter I, Chekmenev D, Krull M, Hornischer K, Voss N, Stegmaier P, Lewicki-Potapov B, Saxel $\mathrm{H}$, Kel AE, Wingender E: TRANSFAC ${ }^{\circledR}$ and its module TRANSCompel ${ }^{\oplus}$ : transcriptional gene regulation in eukaryotes. Nucleic Acids Res 2006, 34:D108-D110.

93. Blancafort P, Segal DJ, Barbas CF: Designing transcription factor architectures for drug discovery. Mol Pharmacol 2004, 66:1361-1371.

94. Heimberger T, Andrulis M, Riedel S, Stühmer T, Schraud H, Beilhack A, Bumm T, Bogen B, Einsele H, Bargou RC, Chatterjee M: The heat shock transcription factor 1 as a potential new therapeutic target in multiple myeloma. Br J Haematol 2013, 160:465-476.

95. Garg A, Aggarwal BB: Nuclear transcription factor-kappaB as a target for cancer drug development. Leukemia 2002, 16:1053-1068.

96. Kucharczak J, Simmons MJ, Fan Y, Gelinas C: To be, or not to be: NF[kappa]B is the answer - role of Rel//NF-[kappa]B in the regulation of apoptosis. Oncogene 2003, 22:8961-8982.

97. Bharti AC, Aggarwal BB: Nuclear factor-kappa B and cancer: its role in prevention and therapy. Biochem Pharmacol 2002, 64:883-888.

98. Konstan MW, Byard PJ, Hoppel CL, Davis PB: Effect of high-dose ibuprofen in patients with cystic fibrosis. New Engl J Med 1995, 332:848-854.

99. Lands LC, Milner R, Cantin AM, Manson D, Corey M: High-dose ibuprofen in cystic fibrosis: Canadian Safety and Effectiveness Trial. J Pediatr 2007, 151:249-254.

100. Liu Z, Fang H, Reagan K, Xu X, Mendrick DL, Slikker W Jr, Tong W: In silico drug repositioning - what we need to know. Drug Discov Today 2013, 18:110-115.

101. FDA Adverse Event Reporting System (FAERS). [http://www.fda.gov/drugs/ guidancecomplianceregulatoryinformation/surveillance/adversedrugeffects/ default.htm]

102. Behrman RE, Benner JS, Brown JS, McClellan M, Woodcock J, Platt R: Developing the Sentinel System - a national resource for evidence development. New Engl J Med 2011, 364:498-499.

103. Hartman M, Martin A, McDonnell P, Catlin A, National Health Expenditure Accounts Team: National health spending in 2007: slower drug spending contributes to lowest rate of overall growth since 1998. Health Aff 2009, 28:246-261.

doi:10.1186/s13073-014-0094-2

Cite this article as: Liu et al:: Deciphering miRNA transcription factor feed-forward loops to identify drug repurposing candidates for cystic fibrosis. Genome Medicine 2014 6:94.

\section{Submit your next manuscript to BioMed Central and take full advantage of:}

- Convenient online submission

- Thorough peer review

- No space constraints or color figure charges

- Immediate publication on acceptance

- Inclusion in PubMed, CAS, Scopus and Google Scholar

- Research which is freely available for redistribution
C Biomed Central 